\title{
Antioxidant properties of Philippine Bignay (Antidesma bunius (Linn.) Spreng cv. 'Common') flesh and seeds as affected by fruit maturity and heat treatment
}

\author{
1, ${ }^{*}$ Castillo-Israel, K.A.T., ${ }^{1}$ Sartagoda, K.J.D., ${ }^{1}$ Ilano, M.C.R., ${ }^{1}$ Flandez, L.E.L., \\ ${ }^{1,2}$ Compendio, M.C.M. and ${ }^{1}$ Morales, D.B. \\ ${ }^{1}$ Institute of Food Science and Technology, College of Agriculture and Food Science, University of the \\ Philippines - Los Baños, Laguna, Philippines 4031 \\ ${ }^{2}$ Department of Science and Technology-Science Education Institute, DOST Compound, Bicutan, Taguig \\ City 1631
}

\section{Article history:}

Received: 11 May 2020

Received in revised form: 12 June 2020

Accepted: 4 July 2020

Available Online: 11 August 2020

\section{Keywords:}

Bignay,

Antioxidants,

Fruit maturity,

Blanching,

Antioxidant activity

DOI:

https://doi.org/10.26656/fr.2017.4(6).215

\begin{abstract}
The effects of maturity (green-unripe, red-ripe, and purple-fully ripe) and heat treatment (blanching at $90 \pm 5^{\circ} \mathrm{C}$ for 2 mins and steaming at $105 \pm 5^{\circ} \mathrm{C}$ for 5 mins) on the antioxidant content and activity of Philippine bignay (Antidesma bunius (Linn.) Spreng cv. 'common') flesh and seeds were investigated. The total phenolic content (TPC), total flavonoid content (TFC) and total anthocyanin content (TAC) were determined using the Folin-Ciocalteau assay, aluminum chloride assay, and $\mathrm{pH}$ differential technique, respectively, and the antioxidant activity was determined using DPPH, ABTS, and FRAP assays. Results showed that the antioxidant content and activity of bignay increased with maturity. Fully ripe flesh and seeds were found to have the highest antioxidant content and activity regardless of the heat treatment applied. The TPC $(8.06 \pm 0.15 \mathrm{mg}$ gallic acid equivalents (GAE)/g), TFC $(8.10 \pm 0.06 \mathrm{mg}$ quercetin equivalents $(\mathrm{QE}) / \mathrm{g})$, TAC $(4.07 \pm 0.03 \mathrm{mg}$ cyanidin-3-glucoside equivalents (CGE)/L extract), and antioxidant activity (ABTS $10.37 \pm 0.04$, DPPH 9.60 \pm 0.10 , FRAP $24.37 \pm 0.53$ Trolox equivalents (TE)/g) of fully ripe seeds were superior when blanched. On the other hand, the TPC $(40.73 \pm 0.04 \mathrm{mg}$ GAE$/ \mathrm{g})$, TFC $(31.54 \pm 0.15 \mathrm{mg} \mathrm{QE} / \mathrm{g})$, TAC $(20.93 \pm 0.12 \mathrm{mg} \mathrm{CGE} / \mathrm{L}$ extract), of fully ripe flesh were superior when not heat-treated while its antioxidant activity (ABTS $34.19 \pm 0.19$, DPPH $14.01 \pm 0.02$, FRAP $87.78 \pm 1.22$ (TE)/g) was highest when blanched but did not vary significantly compared to unheated samples. This study suggested that bignay 'common' variety was a good source of antioxidants particularly the flesh at fully ripe stage. Blanching had shown to enhance its antioxidant activities.
\end{abstract}

\section{Introduction}

Due to the increasing concern in chronic diseases and malnutrition, consumers have recognized the importance of foods having benefits beyond basic nutrition. These foods, known as functional foods, contain physiologically active components that help avert or delay the occurrence of chronic diseases, hence they are promoted as a healthier alternative to conventional foods. An example is brown rice and pigmented rice varieties, whose potential benefits include control of blood sugar due to its high dietary fiber, antioxidant and anticancer due to polyphenolic compounds like catechin, oryzanol, and tocopherol, and anti-beriberi due to high vitamin B content (TecsonMendoza, 2007). Virgin coconut oil is another product that is known to exhibit antioxidant activity that is twice as high as $\alpha$-tocopherol (Dia et al., 2005). Some root crops like sweet potato, taro, purple yam, and cassava were also reported to have high dietary fiber and low glycemic index, indicating their ability to control diabetes mellitus (Trinidad, 2005).

The Philippines supports the diverse growth of fruitbearing trees, most of which are still underutilized. One of them is bignay (Antidesma bunius (Linn.) Spreng), that yields an edible fruit that can be processed into several food products. In the Philippines, the two most abundant varieties are the 'kalabaw' and the 'common' cultivar. The 'kalabaw' cultivar is superior in weight, size, and percent edible portion as compared to the 'common' cultivar. This study will explore the 'common' cultivar since this variety is more abundant and there are limited studies on varietal differences as 
Studies suggest that the fruit exhibits biological effects that are related to a group of polyphenolic compounds called flavonoids (Mojžišová and Kuchta, 2001). In 2015, Jorjong et al. (2015) reported that bignay contains considerable levels of phytochemicals and antioxidant capacity. The fruit was also reported to have antiradical, antiplatelet, anticoagulant, anti-dysenteric, antimicrobial, antihypertensive, anticancer effects, sudorific activities (Islam et al., 2018). The antioxidant activity of dark-colored fruits like bignay rises during maturation as flavonoids accumulate (Macheix et al., 1990). Processing and storage were also reported to affect the antioxidant activity of berries. Michalczyk and Macura (2010) reported that freezing and refrigeration reduced, while pasteurization increased the antioxidant activity of shadblow serviceberry. Heating was found to increase the antioxidant activity of tomatoes, oriental melon, apple, melon, watermelon, and banana (Kim et al., 2008). Boiling, microwaving, and pressure cooking were also found to increase the antioxidant activity of bitter melon (Ng and Kuppusamy, 2019). However, according to Chumyam et al. (2013), boiling, steaming, and microwaving caused a significant decrease in the antioxidant activity of eggplant. This suggests that the effect of processing on the antioxidant activity varies with the commodity.

While the literature is replete with studies on bignay and its functional properties, there are no studies available on particular varieties in the Philippines. The present study aimed to investigate the bioactivities of naturally occurring compounds with antioxidant properties in 'common' variety of bignay fruit as affected by both maturities (unripe, half-ripe and full ripe) and processing technique (blanching and steaming). Results obtained can serve as baseline data for functional food product development studies.

\section{Materials and methods}

\subsection{Chemicals}

Chemicals and reagents that were used in the study which include methanol, distilled water, glacial acetic acid, Folin-Ciocalteau reagent, gallic acid, sodium carbonate, aluminum chloride, quercetin, potassium chloride, hydrochloric acid, sodium acetate trihydrate, $( \pm)$-6-hydroxy-2,5,7,8-tetramethylchromane-2-

carboxylic acid (Trolox), 2,2-diphenyl-1-picrylhydrazyl (DPPH), 2,2'-azino-bis(3-ethylbenzothiazoline-6sulfonic acid) diammonium salt (ABTS), potassium persulfate, 2,4,6-tris(2-pyridyl)-s-triazine (TPTZ) and iron(III) chloride were all analytical and HPLC grade.

\subsection{Preparation of plant material}

Bignay (Antidesma bunius (L.) Spreng cv. 'common') fruits were collected from the province of Laguna, Philippines. Bignay identity was verified by a curator from the Botanical Herbarium, Museum of Natural History, University of the Philippines Los Baños. Gathered fruits were washed with water and divided according to maturity stage based on size and color (Figure 1). Each maturity stage was then subdivided into three portions wherein the first portion was subjected to blanching at $90 \pm 5^{\circ} \mathrm{C}$ for 2 mins, the second portion was subjected to steaming at $105 \pm 5^{\circ} \mathrm{C}$ for 5 mins, and the last portion was left unprocessed. All portions were de-pulped to facilitate separation of the seeds from the flesh and the skin. Both separated seeds and flesh were freeze-dried and ground. The resulting powdered samples were then sieved using a fine mesh strainer and stored inside clean, dark and airtight containers away from direct light.

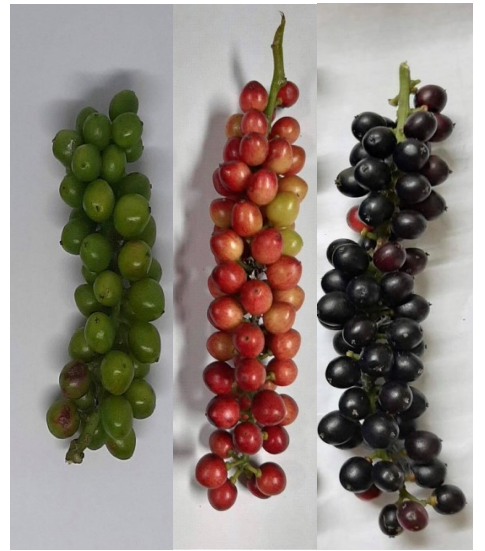

Figure 1. Different ripeness stages of bignay 'common' variety. (L-R): unripe, half-ripe, fully ripe

\subsection{Extraction procedure}

The extraction method described by Larrauri et al. (1997) was followed with minor modifications. Exactly $500 \mathrm{mg}$ powdered freeze-dried samples were extracted using $15 \mathrm{~mL}$ of methanol: water: acetic acid (50:50:1, $\mathrm{v}: \mathrm{v}: \mathrm{v})$ in a shaker for an hour at room temperature. The mixture was then centrifuged for $15 \mathrm{mins}$, and the supernatant was collected and transferred to an amber glass bottle before storing at $0-4^{\circ} \mathrm{C}$. Dilution of samples was done before each analysis.

\subsection{Quantification of total phenolic and flavonoid content}

The total phenolic content (TPC) was analyzed following the method laid by Waterhouse (2002) using Folin-Ciocalteau method but with some modifications. A $0.3 \mathrm{~mL}$ volume of the diluted sample was mixed with $1.5 \mathrm{~mL}$ of $10 \%$ Folin-Ciocalteau reagent and was allowed to stand for 5 mins at room temperature. A 1.2 $\mathrm{mL}$ of $4 \% \mathrm{Na}_{2} \mathrm{CO}_{3}$ was added and the solution was 
vortexed and allowed to stand for 90 mins before the absorbance was read at $760 \mathrm{~nm}$.

For total flavonoid content (TFC) quantification, a modified method following the aluminum chloride assay of Luximon-Ramma et al. (2002) was used wherein a 2.5 $\mathrm{mL}$ of the diluted sample was mixed with $0.5 \mathrm{~mL}$ of $10 \%$ $\mathrm{AlCl}_{3}$ solution. The mixture was allowed to stand for 15 mins at room temperature to facilitate reaction before reading its absorbance at $367.5 \mathrm{~nm}$.

For TPC and TFC standards, methanolic solutions of gallic acid and quercetin $(3-100 \mu \mathrm{g} / \mathrm{mL})$ were used, respectively. Results were expressed as milligrams standard per gram freeze-dried sample as shown in Equation 1.

$$
\mathrm{A}=\mathrm{cv} / \mathrm{m}
$$

Where $\mathrm{A}=$ name of the assay, $\mathrm{c}=$ concentration $(\mu \mathrm{g} /$ $\mathrm{mL}$ ) of the standard established from the calibration curve, $\mathrm{v}=$ volume $(\mathrm{mL})$ of the extract solution and $\mathrm{m}=$ weight $(\mathrm{g})$ of extract

\subsection{Quantification of total anthocyanin content}

Quantification of total anthocyanin content (TAC) of samples was conducted using the $\mathrm{pH}$ differential method of Lee et al. (2005). Samples were diluted to a minimum dilution factor of 5 using potassium chloride buffer $(0.025 \mathrm{M}, \mathrm{pH} 1.0)$ and sodium acetate buffer $(0.40 \mathrm{M}$, $\mathrm{pH}$ 4.5). In choosing the dilution factor, the absorbance reading of samples diluted with $\mathrm{pH} 1.0$ buffer at $520 \mathrm{~nm}$ should be around $0.2-1.2 \mathrm{AU}$. The absorbances of the extracts diluted with $\mathrm{pH} 1.0$ and $\mathrm{pH} 4.5$ buffer were then read at $520 \mathrm{~nm}$ and $700 \mathrm{~nm}$ against a blank of distilled water. The total anthocyanin content (mg cyanidin-3glucoside equivalents/L extract) was computed using Equation 2.

$$
\mathrm{TAC}(\mathrm{mg} / \mathrm{L})=\mathrm{A} * \mathrm{MW} * \mathrm{DF}^{*}\left(1000 /\left(\mathrm{e}^{*} \mathrm{~L}\right)\right)
$$

Where $A=$ absorbance $\left(\mathrm{A}_{510 \mathrm{~nm}}-\mathrm{A}_{700 \mathrm{~nm}}\right) \mathrm{pH} 1.0-\left(\mathrm{A}_{510 \mathrm{~nm}}\right.$ $\left.\mathrm{A}_{700 \mathrm{~nm}}\right) \mathrm{pH} 4.5, \mathrm{MW}=$ molecular weight of cyanidin-3glucoside $(433.2 \mathrm{~g} / \mathrm{mol}), \mathrm{DF}=$ dilution factor, $\mathrm{e}=$ extinction coefficient of cyanidin 3-glucoside $(31,600 \mathrm{~L}$ $\left.\mathrm{mol}^{-1} \mathrm{~cm}^{-1}\right)$, and $\mathrm{L}=$ cell path length $(1 \mathrm{~cm})$.

\subsection{DPPH radical scavenging activity assay}

DPPH radical scavenging activity assay was performed following the method of Pisoschi and Negulescu (2011) with some modifications. A $1.0 \mathrm{~mL}$ volume of the diluted sample was mixed with $1.0 \mathrm{~mL}$ of absolute methanol and $1.0 \mathrm{~mL}$ of freshly prepared DPPH solution. The standards used were methanolic solutions of Trolox $(1-10 \mu \mathrm{g} / \mathrm{mL})$. Sample absorbance was then read at $517 \mathrm{~nm}$ against a blank of absolute methanol.
Results were expressed as milligrams Trolox equivalents per gram of freeze-dried sample.

\subsection{ABTS assay}

A modified method of TEAC evaluation was used following the established assay of Tomasina et al. (2012). A $0.25 \mathrm{mM}$ ABTS solution with $3.45 \mathrm{mM}$ potassium persulfate was prepared for ABTS radical cation. The solution was stored inside a light-protected container and was allowed to stand for $12-16 \mathrm{hrs}$ at $4^{\circ} \mathrm{C}$ before it was used. Dilution of stock solution with methanol followed until an absorbance reading of $0.70 \pm 5$ at $734 \mathrm{~nm}$ was attained. A $2.7 \mathrm{~mL}$ volume of the diluted stock was then added to a $0.3 \mathrm{~mL}$ diluted sample and was left to stand for 15 mins in the dark at room temperature. The standards used were methanolic solutions of Trolox $(2-40 \mu \mathrm{g} / \mathrm{mL})$. The absorbance was then read at $734 \mathrm{~nm}$ and the results were expressed as milligrams Trolox equivalents per gram of freeze-dried sample.

\subsection{Ferric reducing antioxidant power (FRAP) assay}

The method of Tomasina et al. (2012) was followed with some modifications. A $2.7 \mathrm{~mL}$ volume of freshly prepared FRAP reagent $(300 \mathrm{mM}$ acetate buffer $(\mathrm{pH}$ 3.6): $10 \mathrm{mM}$ TPTZ $(10 \mathrm{mM}): 20 \mathrm{mM} \mathrm{FeCl}_{3}$ solution $(10: 1: 1, \mathrm{v}: \mathrm{v}: \mathrm{v}))$ was added to $0.3 \mathrm{~mL}$ of the diluted sample. The mixture was then incubated for 5 mins at $37^{\circ} \mathrm{C}$ to facilitate reaction before the absorbance was read at $620 \mathrm{~nm}$. The standards used were methanolic solutions of Trolox $(3-100 \mu \mathrm{g} / \mathrm{mL})$. Results were reported as milligrams Trolox equivalents per gram of freeze-dried sample.

\subsection{Statistical analysis}

A completely randomized design was used in the experiment and the results were presented as mean \pm SEM computed from three values. Using factorial ANOVA, the influence of maturity stage and processing treatment on the TPC, TFC, TAC and antioxidant activities (ABTS, DPPH, and FRAP) of bignay seeds and flesh was analyzed. Tukey's Honest Significant Difference (HSD) test was used to test differences among the treatments. All statistical analyses were conducted using Minitab 19.0 for Windows with the significance level set at 0.05 .

\section{Results}

3.1 Effect of maturity and processing method on the TPC, TFC and TAC of bignay seeds

ANOVA (Analysis of Variance) results show that maturity and processing method significantly influence the antioxidant content of bignay seeds $(\mathrm{p}<0.05)$. Maturity and processing method were also found to 
interact significantly. Figure 2 shows that the total phenolic, total flavonoid and total anthocyanin content of bignay seeds generally increased with maturity for all the processing methods applied. The TPC, TFC, and TAC of fully ripe seeds increased by as much as $116 \%, 53 \%$, and $7 \mathrm{E}+20 \%$, respectively, compared to unripe seeds. In addition, heat-treated samples yielded higher antioxidant content than the fresh seeds. The TPC, TFC, and TAC of fully ripe seeds increased by $85 \%, 61 \%$, and $206 \%$, respectively, when blanched and by $40 \%, 25 \%$, and $75 \%$, respectively, when steamed compared to unheated samples.

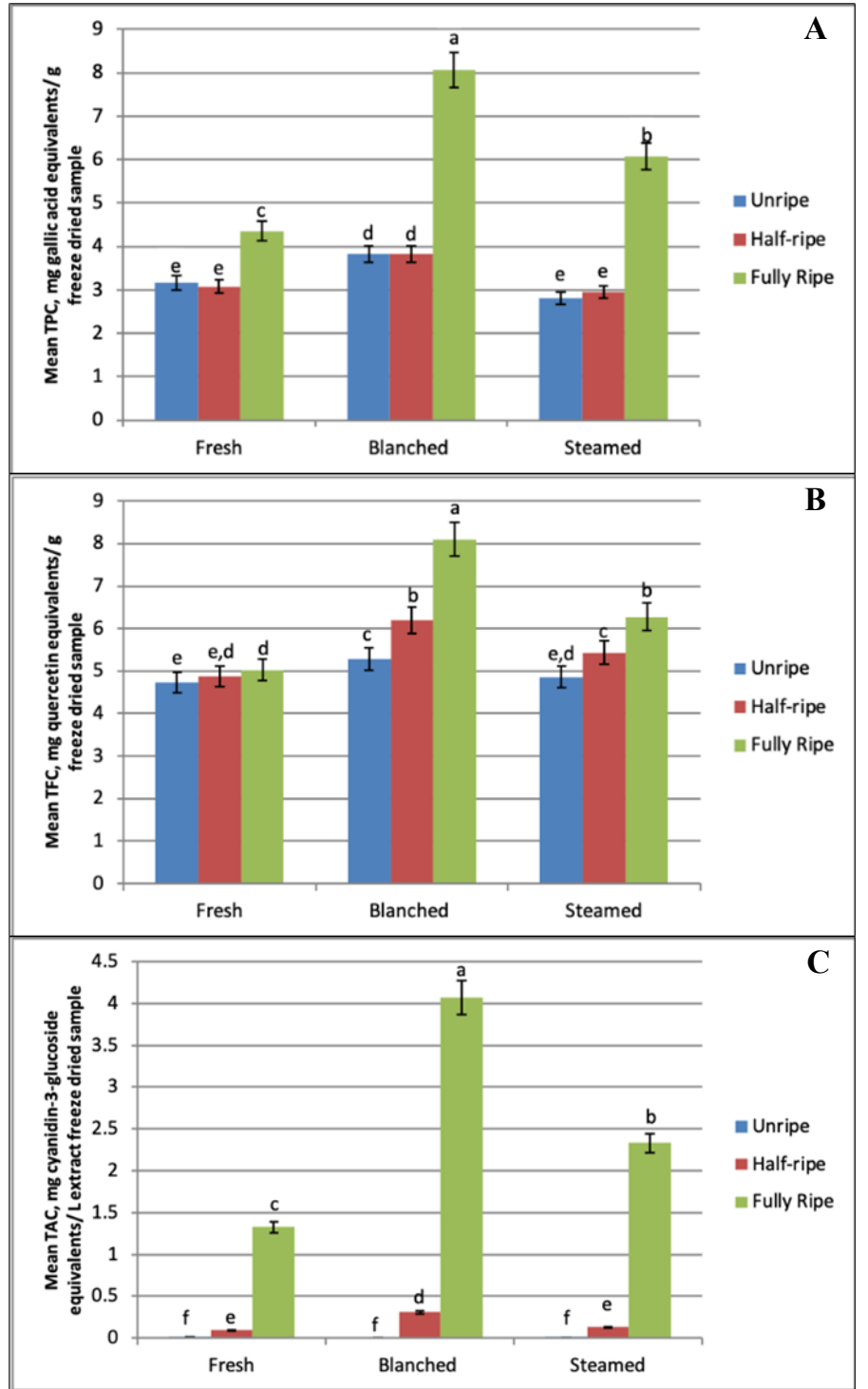

Figure 2. Total phenolic content (A), total flavonoid content (B) and total anthocyanin content (C) of bignay seeds as affected by maturity and processing method before freezedrying (mean \pm SEM). Different lower-case letters indicate a significant difference $(\mathrm{p}<0.05$; Tukey's test)

3.2 Effect of maturity and processing method on antioxidant activity (ABTS, DPPH, and FRAP) of bignay seeds

The antioxidant activity (ABTS, DPPH, and FRAP) of bignay seeds was significantly influenced by maturity and processing method. The variables were also found to have a significant interaction $(p<0.05)$. Figure 3 shows that the antioxidant activity of bignay seeds generally increased with maturity level. Fully ripe bignay seeds exhibited the highest antioxidant activity among the maturity stages in all the processing methods applied. The antioxidant activity of fully ripe seeds increased by at least $90 \%$ compared to unripe seeds. Blanching significantly increased the antioxidant activity of the fully ripe seeds by at least $95 \%$ while steaming brought about at least $59 \%$ increase as compared to fresh samples.

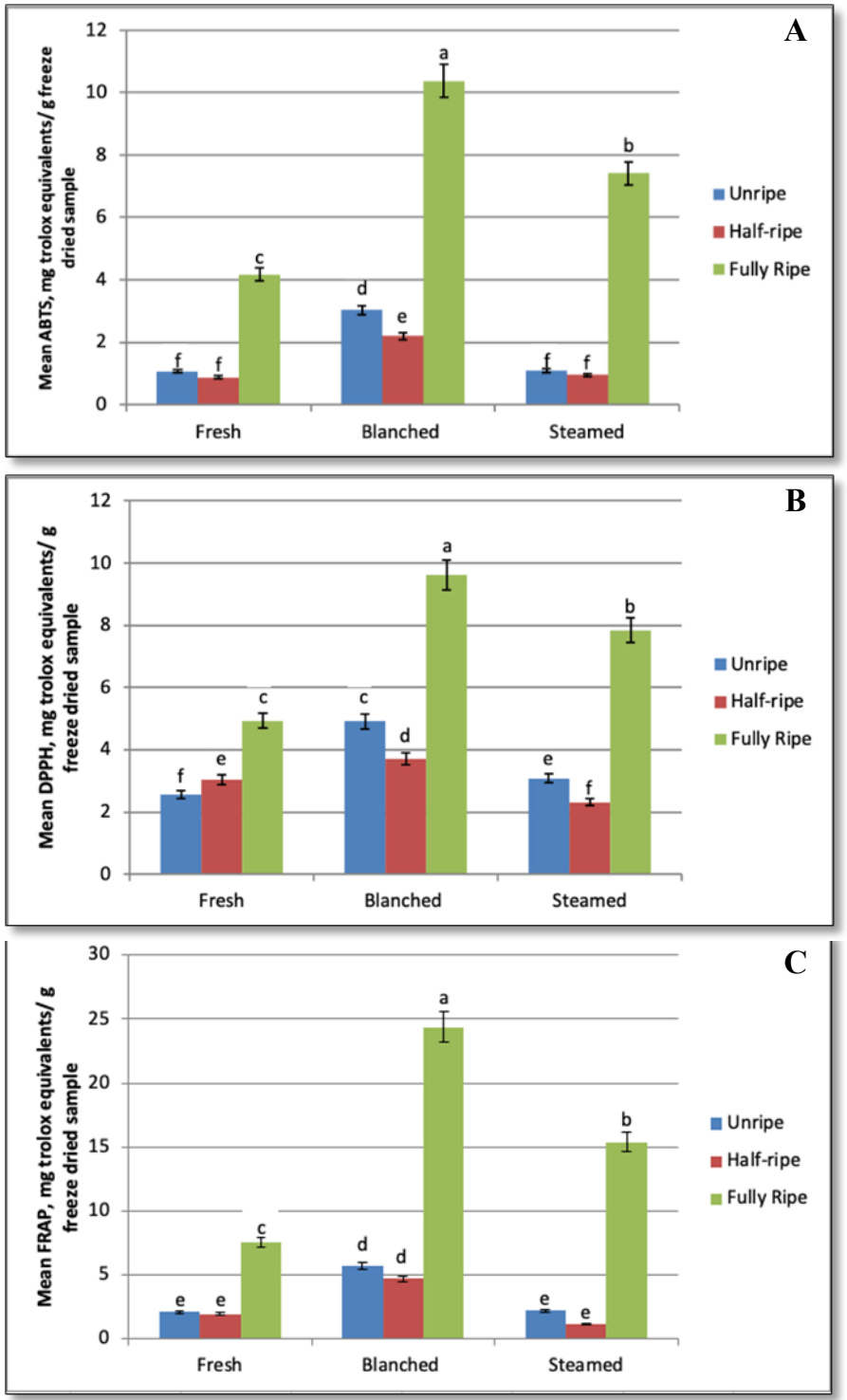

Figure 3. Antioxidant activities of bignay seeds shown in $\mathrm{mg}$ Trolox equivalents per $\mathrm{g}$ freeze-dried sample determined using ABTS (A), DPPH (B), and FRAP (C) assays as affected by maturity and processing method before freeze-drying (mean \pm SEM). Different lower-case letters indicate a significant difference $(p<0.05$; Tukey's test $)$

\subsection{Effect of maturity and processing method on the} TPC, TFC and TAC of bignay flesh

The interaction between maturity and processing method was also found to be statistically significant $(\mathrm{p}<$ 
0.05). The antioxidant content of bignay flesh was also significantly influenced by the two variables. As with the seeds, the antioxidant content of the flesh increased with the maturity level. An increase of at least 184\%, 120\%, and $1 \mathrm{E}+4 \%$ was observed in the TPC, TFC, and TAC, respectively, of fully ripe flesh, compared to unripe flesh. Figure 4 illustrates that the antioxidant content decreased as heat is applied, especially in fully ripe flesh. The TPC, TFC, and TAC of fully ripe flesh decreased by $45 \%, 43 \%$, and $26 \%$, respectively, when steamed and by $40 \%, 35 \%$, and $93 \%$, respectively, when blanched.

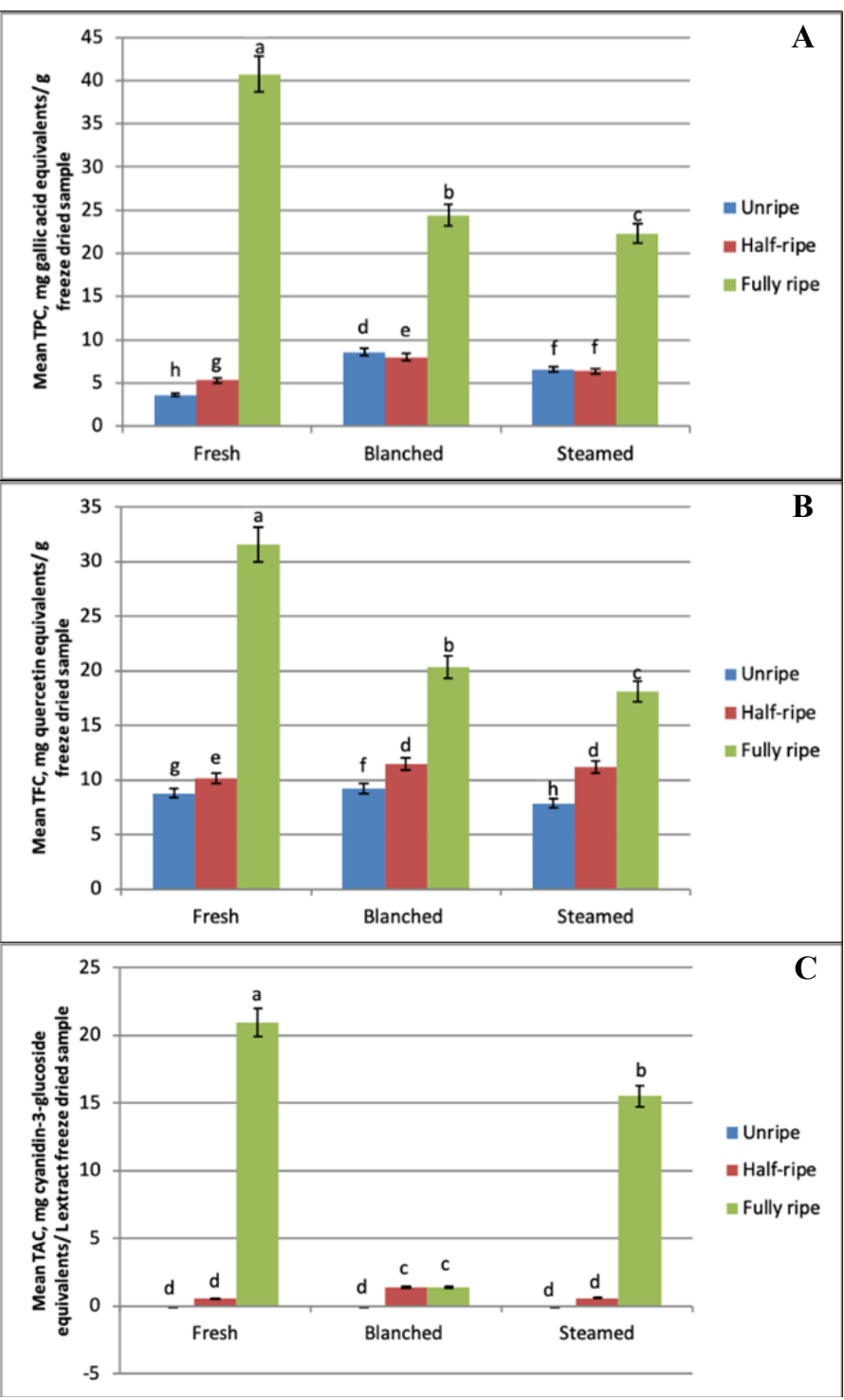

Figure 4. Total phenolic content(A), total flavonoid content(B) and total anthocyanin content $(\mathrm{C})$ of bignay flesh as affected by maturity and processing method before freeze-drying (mean \pm SEM). Different lower-case letters indicate a significant difference $(\mathrm{p}<0.05$; Tukey's test)

3.4 Effect of maturity and processing method on antioxidant activities (ABTS, DPPH, and FRAP) of bignay flesh.

Results of the ANOVA also show that maturity and processing method significantly influence the antioxidant activity of bignay seeds $(\mathrm{p}<0.05)$. Maturity and processing method were also found to interact significantly. The same trend was observed as with the seeds. The antioxidant activity of the flesh generally increased with maturity level. At least $58 \%$ increase in the antioxidant activity of fully ripe bignay flesh was observed as compared to unripe flesh. As observed in Figure 5, heat treatment increased the antioxidant activity of half-ripe and unripe flesh while that of fully ripe was generally not significantly affected.
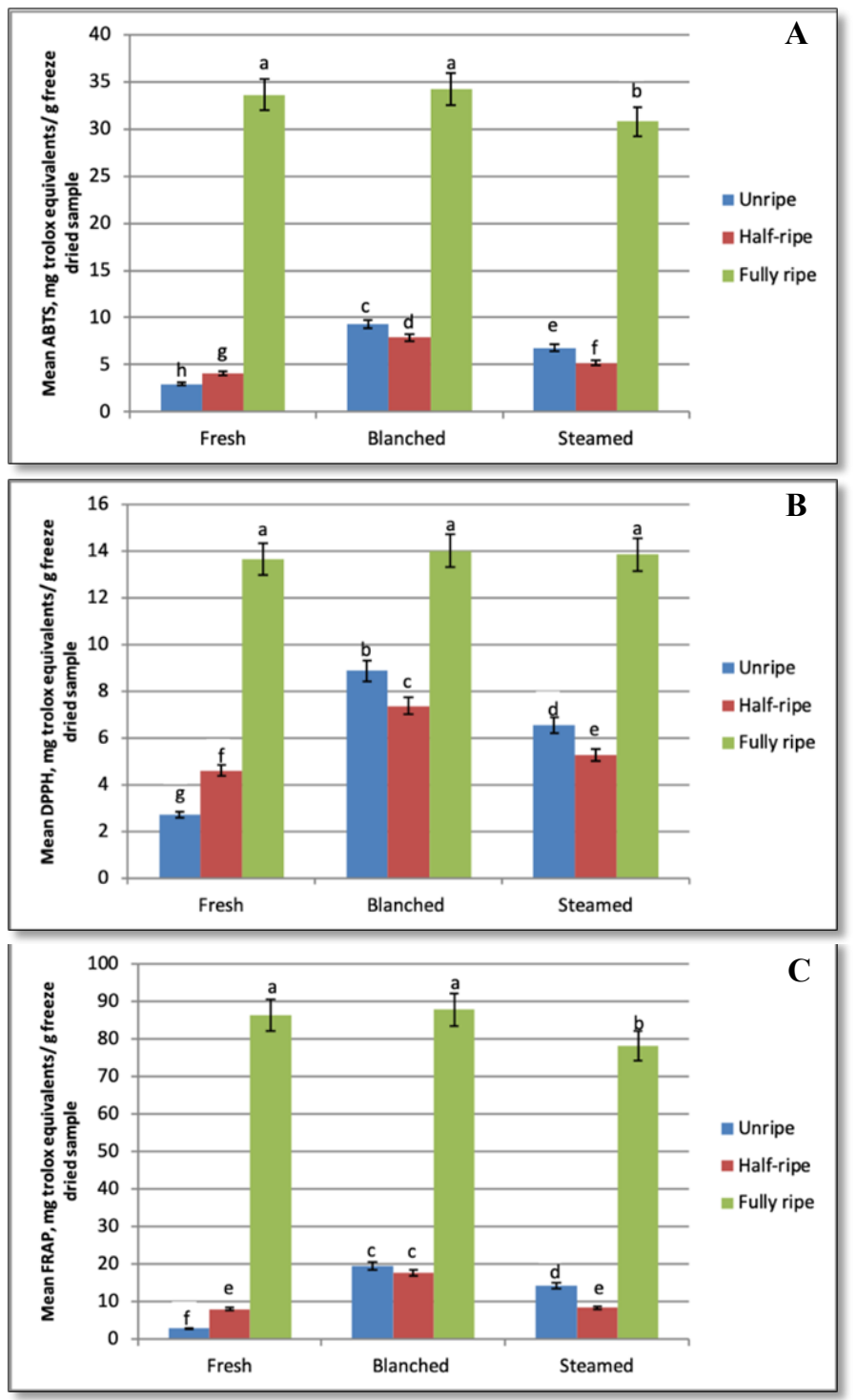

Figure 5. Antioxidant activities of bignay flesh shown in $\mathrm{mg}$ Trolox equivalents per $\mathrm{g}$ freeze-dried sample determined using ABTS (A), DPPH (B), and FRAP (C) assays as affected by maturity and processing method before freeze-drying (mean \pm SEM). Different lower-case letters indicate a significant difference $(\mathrm{p}<0.05$; Tukey's test).

\section{Discussion}

The processing history of fruits and vegetables have been well known to affect their over-all beneficial capacity. Processing steps and techniques such as peeling, slicing, freezing, blanching, steaming, drying, pulverizing may have positive or negative effects on the food's organoleptic and nutritional properties. Before, 
heat treatment was believed to instigate a decrease in antioxidant compounds in fruits and vegetables (Jonsson, 1991) but recent studies showed that processing may increase the bioavailability of some antioxidants (Kaur and Kapoor, 2001). Hence, this study was conducted to highlight the effect of different maturity stages and processing techniques such as blanching and steaming on the antioxidant profile of the 'common' variety of bignay.

Results of the ANOVA showed that both maturity stage and processing technique have a significant effect on the antioxidant content (TPC, TFC, and TAC), and antioxidant activity (measured using DPPH, ABTS and FRAP assay) of 'common' bignay flesh and seeds at $\alpha=$ 0.05 . This may be attributed to the changing proportion of phenolic compounds in the flesh and seeds as the fruit matures. Existing literature showed similar findings in five blueberry cultivars where the anthocyanin and total phenolic content, and the antioxidant activity increased with maturity level. As cited by Eichholz et al. (2015), the synthesis of anthocyanins in blueberry tissues was correlated with the expression of the flavonoid pathway genes during fruit ripening. Thus, anthocyanin was perceived to be the second most prevalent phenolic compound in blueberry fruit during harvesting. Figures $2,3,4$, and 5 illustrate that fully ripe bignay exhibited the highest antioxidant content and activity among the other maturity stages regardless of the processing technique applied. This is in agreement with the study by Fuentes et al. (2016) in Arrayan berry (Luma apiculata) and Ndou et al. (2019) in natal plum (Carissa macrocarpa) wherein a positive correlation in the antioxidant profile of these fruits were also noted. A better antioxidant profile can be associated with increasing maturity. It can be inferred from the results that to maximize the use of antioxidants present in bignay, fully ripe fruits should be selected for consumption and/or processing.

Processing technique may also play an important role as phenolic compounds are understood to respond differently depending on the processing method applied (Fischer et al., 2011; N'Dri et al., 2013). Blanched samples exhibited higher antioxidant content and activity than the untreated samples. In food processing, blanching is considered as one of the important steps used to treat samples either to soften the product, inactivate enzymes that will cause browning or inhibit other possible reactions in fruits and vegetables. Rossi et al. (2003) reported that steam blanching blueberries for three mins resulted in higher anthocyanin retention $(23 \%)$ compared to unblanched samples $(12 \%)$ during juice processing. Spanos et al. (1990) also stated that the change in anthocyanin content may be caused by an increased extraction efficiency in softened fruits. High temperature enhances membrane permeability in the macerated peels leading to an improved phenolic extraction and release of bound phenolic compounds. Blanching opens up the cell matrix causing an increase in the polyphenol yield during extraction, that may either enhance or reduce the antioxidant activity. Thus, for bignay seeds, blanching method can be well- established to enhance its antioxidative potential. Although blanching was found to have a positive effect on the antioxidant content (Figure 2) and antioxidant activity (Figure 3) of bignay seeds, it can be observed that blanching resulted in a negative effect on the antioxidant content of bignay flesh. Figure 4 illustrates a noticeable decrease in TPC, TFC and TAC of flesh samples when subjected to heat treatment. This may be due to the differences in the composition of polyphenols among seeds, peels, and flesh of the samples. A study by Yilmaz et al. (2014) reported that grape's skin, pulp and seeds contain a large amount of diverse phenolic compounds and that a large number of these compounds may exhibit beneficial antioxidant properties. The skin of the berry mainly contains flavonoids while both skin and seeds hold flavan-3-ols (catechins and proanthocyanidins).

Although the TPC, TFC and TAC decreased, the antioxidant activity of the flesh was observed to have no significant difference from the control sample (Figure 5). According to Wang and Cao (1996), fruits may have varying antioxidant components and their relative quantities may also vary, thereby affecting the total antioxidant capacity of fruits. In relation to this, different bioactive compounds present in the system can probably provide either an increase or decrease in the antioxidant activity. Having said this, the antioxidant activity of bignay flesh may not be limited to its phenolic, flavonoid and anthocyanin content. Since the heat treatment applied to bignay flesh did not negatively alter its antioxidant activity, it can still be concluded that heat treatment can be used to maximize the antioxidant potential of 'common' bignay flesh.

\section{Conclusion}

The research was able to conclude a significant effect of both fruit maturity and heat treatment on the antioxidant content and activity of bignay 'common' flesh and seed. As bignay fruit ripens, the antioxidant content and activity of both flesh and seeds increase. Heat treatment, specifically blanching, increased antioxidant activity. Comparing the levels of antioxidants and antioxidant activities between flesh and seeds, much lower levels were obtained from the seeds. Therefore, bignay flesh provides most of the antioxidants of the fruit. In general, bignay 'common' variety can be 
considered as a valuable source of antioxidants particularly the flesh at the fully ripe stage. Blanching is recommended as a pre-processing treatment to further enhance its antioxidant properties when used in the development of functional foods.

\section{Acknowledgment}

The authors would like to acknowledge the Philippine Council for Health Research and Development of the Department of Science and Technology (DOST- PCHRD), Philippines for funding this research.

\section{References}

Chumyam, A., Whangchai, K., Jungklang, J., Faiyue, B. and Saengnil, K. (2013). Effects of heat treatments on antioxidant capacity and total phenolic content of four cultivars of purple skin eggplants. Science Asia, 39(3), 246-251. https://doi.org/10.2306/ scienceasia1513-1874.2013.39.246

Dia, V.P., Garcia, V.V., Mabesa, R.C. and TecsonMendoza, E.M. (2005). Comparative physicochemical characteristics of virgin coconut oil produced by different methods. Philippines Agricultural Scientist, 88(4), 462-475.

Eichholz, Ines, Huyskens-Keil, Susanne and Rohn, Sascha. (2015). Blueberry Phenolic Compounds: Fruit Maturation, Ripening and Post-Harvest Effects. In Preedy, V. (Ed.) Processing and Impact on Active Components in Food, p. 700. USA: Academic Press. https://doi.org/10.1016/B978-0-12-404699-3.000214

Fischer, U.A., Dettmann, J.S., Carle, R. and Kammerer, D.R. (2011). Impact of processing and storage on the phenolic profiles and contents of pomegranate (Punica granatum L.) juices. European Food Research and Technology, 233, 797. https:// doi.org/10.1007/s00217-011-1560-3

Fuentes, L., Valdenegro, M., Gómez, M.G., Ayala-Raso, A., Quiroga, E., Martínez, J.P. and Figueroa, C.R. (2016). Characterization of fruit development and potential health benefits of arrayan (Luma apiculata), a native berry of South America. Food Chemistry, 196, 1239-1247. https://doi.org/10.1016/ j.foodchem.2015.10.003

Islam, M.S., Ahammed, M.S. and Sukurno, F. I. (2018). A Review on Phytochemical and Pharmacological Potentials of Antidesma bunius. Journal of Analytical and Pharmaceutical Research, 7(5), 602604. https://doi.org/10.15406/japlr.2018.07.00289

Jonsson, I. (1991). Thermal degradation of carotenoids and in uence of their physiological functions. In
Friedman, M. (Ed.) Nutrition and Toxicologycal Consequences of Food Processing, p. 75-82. New York, NY, USA: Plenum Press. https:// doi.org/10.1007/978-1-4899-2626-5_6

Jorjong, S., Butkhup, L. and Samappito, S. (2015). Phytochemicals and antioxidant capacities of MaoLuang (Antidesma bunius L.) cultivars from Northeastern Thailand. Food Chemistry, 181, 248255. https://doi.org/10.1016/j.foodchem.2015.02.093

Kaur, C. and Kapoor, H. (2001). Antioxidants in Fruits and Vegetables- The Millennium's Health. International Journal of Food Science and Technology, 36(7), 703-725. https://doi.org/10.1046/ j.1365-2621.2001.00513.x

Kim, H.-Y., Woo, K.-S., Hwang, I.-G., Lee, Y. and Jeong, H.-S. (2008). Effects of Heat Treatments on the Antioxidant Activities of Fruits and Vegetables. Korean Journal of Food Science and Technology, 40 (2), 166-170.

Larrauri, J.A., Ruperez, P. and Saura-Calixto, F. (1997). Effect of drying temperature on the stability of polyphenols and antioxidant activity of red grape pomace peels. Journal of Agricultural and Food Chemistry, 45, 1390-1393. https://doi.org/10.1021/ jf960282f

Lee, J., Durst, R.W. and Wrolstad, R.E. (2005). Determination of total monomeric anthocyanin pigment content of fruit juices, beverages, natural colorants, and wines by the $\mathrm{pH}$ differential method: Collaborative study. Journal of AOAC International, 88(5), 1269-1278. https://doi.org/10.1093/ jaoac/88.5.1269

Luximon-Ramma A., Bahorun, T., Soobrattee, M.A. and Arouma, O.I. (2002). Antioxidant activities of phenolic, proanthocyanidin and flavonoid components in extracts of Cassia fistula. Journal of Agricultural and Food Chemistry, 50, 5042-5047. https://doi.org/10.1021/jf0201172

Macheix, J-J., Fleuriet, A. and Billot, J. (1990). Phenolic composition of individual fruits. In Fruit Phenolics. $1^{\text {st }}$ ed, p. $105-148$. Boca Raton, Florida, USA: CRC Press.

Michalczyk, M. and Macura, R. (2010). Effect of processing and storage on the antioxidant activity of frozen and pasteurized shadblow serviceberry (Amelanchier canadensis). International Journal of Food Properties, 13(6), 1225-1233. https:// doi.org/10.1080/10942910903013407

Mojžišová, G. and Kuchta, M. (2001). Dietary flavonoids and risk of coronary heart disease. Physiological Research, 50(6), 529-535. 
Ndou, A., Tinyani, P.P., Slabbert, R.M., Sultanbawa, Y. and Sivakumar, D. (2019). An integrated approach for harvesting Natal plum (Carissa macrocarpa) for quality and functional compounds related to maturity stages. Food Chemistry, 293, 499-510. https:// doi.org/10.1016/j.foodchem.2019.04.102

N'Dri, D., Mazzeo, T., Zaupa, M., Ferracane, R., Fogliano, V. and Pellegrini, N. (2013). Effect of cooking on the total antioxidant capacity and phenolic profile of some whole-meal African cereals. Journal of the Science of Food and Agriculture, 93 (1), 29-36. https://doi.org/10.1002/jsfa.5837

Ng, Z.X. and Kuppusamy, U.R. (2019). Effects of different heat treatments on the antioxidant activity and ascorbic acid content of bitter melon, Momordica charantia. Brazilian Journal of Food Technology, 22, e2018283. https:// doi.org/10.1590/1981-6723.28318

Pisoschi, A.M. and Negulescu, G.P. (2011). Methods for Total Antioxidant Activity Determination: A Review. Biochemistry and Analytical Biochemistry, 1(1), 1000106. https://doi.org/10.4172/21611009.1000106

Rossi, M., Giussani, E., Morelli, R., Lo Scalzo, R., Nani, R.C. and Torreg-Giani, D. (2003). Effect of fruit blanching on phenolics and radical scaveng- ing activity of highbush blueberry juice. Food Research International, 36(9-10), 999-1005. https:// doi.org/10.1016/j.foodres.2003.07.002

Spanos, G.A., Wrolstad, R.E. and Heatherbell, D.A. (1990). Influence of processing and storage on the phenolic composition of apple juice. Journal of Agriculture and Food Chemistry, 38, 1572-1579. https://doi.org/10.1021/jf00097a031

Tecson-Mendoza, E.M. (2007). Development of functional foods in the Philippines. Food Science and Technology Research, 13(3), 179-186. https:// doi.org/10.3136/fstr.13.179

Tomasina, F., Carabio, C., Celano L. and Thomson, L. (2012). Analysis of two methods to evaluate antioxidants. Biochemistry and Molecular Biology Education, 40(4), 266-270. https://doi.org/10.1002/ bmb. 20617

Trinidad, T.P. (2005). Dietary fiber in coconut flour, local root crops and legumes as promising functional foods presented at the "Symposium on the Development Prospects of Functional Foods in the Philippines: Research and Regulatory Issues" February 6, 2004. Manila, Philippines.

Wang, H. and Cao, G. (1996). Prior RL. Total antioxidant capacity of fruits. Journal of Agriculture and Food Chemistry, 44, 701-705. https:// doi.org/10.1021/jf950579y

Yilmaz, Y., Göksel, Z., Erdogan, S.S., Öztürk, A., Arif, A. and Özer, C. (2014). Antioxidant activity and phenolic content of seed, skin and pulp parts of 22 grape (Vitis vinifera L.) Cultivars (4 common and 18 registered or candidate for registration). Journal of Food Processing and Preservation, 39(6), 16821691. https://doi.org/10.1111/jfpp.12399 